Thorax (1976), 31, 181.

\title{
Free internal mammary artery for coronary bypass
}

\author{
BER NARDOA. VIDNE, ARTHUR B. LEE, Jr, \\ THOMASZ. LA JOS, and GEORGE SCHIMERT \\ Department of Surgery, Buffalo General Hospital and The State University of New York \\ at Buffalo, New York 14203, USA
}

\begin{abstract}
Vidne, B. A., Lee, A. B. Jr., Lajos, T. Z., and Schimert, G. (1976). Thorax, 31, 181-184. Free internal mammary artery for coronary bypass. An improved technique of free internal mammary artery (IMA) to ascending aorta anastomosis for coronary bypass is described. A small patch vein with a suitable side branch or branches is interposed, connecting the proximal end of a detached IMA to the ascending aorta.

A single or double free IMA alone or in combination with an additional saphenous vein graft was performed in 77 patients. A total of 125 free IMA grafts were done. The hospital mortality was $2.7 \%$ and late mortality $1.4 \%$. Seventy-one of the 74 surviving patients had no angina and returned to a normal life. Postoperative coronary arteriography in 65 patients showed a patency rate of $96 \%$.

One year's experience with this technique is very encouraging. However, prolonged follow-up is necessary to determine if free IMA, as used by us, will increase the long-term patency rate.
\end{abstract}

Several years' experience with aortocoronary bypass grafts, using reversed saphenous vein segments, revealed an occlusion rate of 15 to $35 \%$ during the first three years (Grondin et al., 1972; Kouchoukos, Kirklin, and Oberman, 1974; Walker et al., 1974). The internal mammary artery (IMA) to coronary artery anastomosis was reported by us and others to have a less than $5 \%$ accumulative occlusion rate (Greene, 1972; Loop et al., 1973; Schimert et al., 1975; Vidne et al., 1975. Unfortunately, the use of IMA has its limitations. Only the anterior descending and the first diagonal coronary artery can be grafted safely, provided the heart is not enlarged. Occasionally, the right coronary artery can be grafted if the obstruction is in the first portion of this vessel. When the internal mammary arteries are detached from their origin, greater mobility can be achieved, and practically all coronary arteries can be reached by anastomosing the IMA to the ascending aorta. However, direct anastomosis of a small, thin-walled vessel to a much larger and thicker aortic wall, often deformed by atherosclerotic changes, may produce functional as well as anatomical stenosis, which in turn results in thrombosis. In order to overcome this problem, we therefore anastomosed the free IMA to the ascending aorta by interposition of a vein patch with a side branch. This arrangement creates a coronary ostium type of exit for the IMA.

The present report describes the technique and results in 77 patients who underwent myocardial revascularization by free IMA grafts.

\section{PATIENTS}

Seventy-seven patients underwent myocardial revascularization by free IMA grafts during 1974 . Fifty-five were men and 22 were women. The patients' ages ranged from 32 to 68 years.

The preoperative symptoms are listed in Table I. Angiographic evidence of $75 \%$ or greater obstruction in a major coronary artery was present in each patient. Ten patients had one coronary vessel involved, 26 patients had two vessels involved, and 41 patients had three or more major arteries involved (Table II). The left ventricular

T A B L E I PREOPERATIVE CLINICAL SYMPTOMS

\begin{tabular}{l|c}
\hline \multicolumn{1}{|c|}{ Symptom } & No. \\
\hline Angina on exercise & 77 \\
Angina at rest & 52 \\
Pre-infarction angina & 16 \\
Heart failure & 6 \\
Arrhythmia & 1 \\
\hline
\end{tabular}


T A B L E I I

PREOPERATIVE CORONARY ARTERIOGRAPHIC FINDINGS

\begin{tabular}{c|cc}
\hline Vessel Disease & No. of Patients & $\%$ \\
\hline Single & 10 & 13 \\
Double & 26 & 41 \\
Triple or more & 41 & 53 \\
\hline
\end{tabular}

ejection fraction (EF) in 17 patients was good, in 44 patients it was fair, and in 16 patients it was poor (Table III). Single free IMA was inserted in 13 patients. Single free IMA in combination with one or two saphenous vein grafts were used in 16 patients. Sixteen patients had double free IMA grafts alone, and 32 patients had double free IMA grafts in combination with one or two saphenous vein grafts (Table IV). In 77 patients a total of 125 free IMA grafts and 61 saphenous vein grafts were performed.

T A B L E I I I

PREOPERATIVE EJECTION FRACTION

\begin{tabular}{c|cc}
\hline Ejection Fraction & No. of Patients & $\%$ \\
\hline Good $(>50 \%)$ & 17 & 22 \\
Fair $(50-35 \%)$ & 44 & 57 \\
Poor $(<35 \%)$ & 16 & 21 \\
\hline
\end{tabular}

T A B L E I V

\begin{tabular}{l|r}
\hline \multicolumn{1}{c|}{ Type of Graft } & No. \\
\hline Left anterior descending & 55 \\
Diagonal branches of LAD & 9 \\
Main circumflex & 2 \\
Marginal branches of circumflex & 43 \\
Right coronary & 16 \\
\hline Total & 125 \\
\hline
\end{tabular}

The free IMA was anastomosed to the left anterior descending (LAD) artery in 55 patients, to the diagonal branches of the LAD in 9 patients, to the main circumflex artery in 2 patients, to marginal branches of the circumflex artery in 43 patients, and to the right coronary artery in 16 patients (Table V).
OPERATIVE TECHNIQUE

The internal mammary arteries are mobilized from the chest wall using the Favoloro self-retaining retractors. The location of the IMA is verified by inspection and palpation. With an electrocautery, a longitudinal incision is made $1 \mathrm{~cm}$ medial to the artery at the level of the fourth costal cartilage. The proper plane of dissection is identified and the artery, including the veins, fascia, and muscle, is elevated. Dissection is carried out proximally to the origin of the vessel and distally to the level of the diaphragm. Special care is taken not to cauterize too near the artery with high-intensity current in order to avoid injury to the vessel wall. When detaching the IMA from the subclavian artery, the phrenic nerve must be visualized and protected from injury. The lumen of the IMA is distended with heparinized blood. Bleeding or visible branches, even if coagulated satisfactorily, are ligated.

A suitable piece of saphenous vein with one or two side-branches is used as a patch which should measure about $2 \times 1.5 \mathrm{~cm}$. The side-branch (or branches) is then cut off about $1 \mathrm{~mm}$ from the vein wall, and the proximal end of the free IMA graft is anastomosed to this branch using 7-0 interrupted sutures. We have generally incised the wall of the IMA graft for about $2 \mathrm{~mm}$ to make the opening commensurable in size to the distal end (Fig. 1). The endothelial surface of the anastomosed vessel can be inspected before it is sutured to the aorta. Inward bulging of the IMA lumen thus detected can be corrected at this time. Any vein valve close to the anastomosis is excised. The vein patch is then sutured to the aorta with 6-0 continuous sutures using an appropriate size aortotomy (Fig. 2). If two free IMA grafts are used, they are anastomosed to the aorta either by individual patches or by using a patch with two side branches. The distal end of the free IMA graft is anastomosed to the coronary artery with 7-0 continuous or interrupted sutures.

T A B L E V

GRAFTING PROCEDURES IN 77 PATIENTS

\begin{tabular}{|c|c|c|c|c|}
\hline \multirow[b]{2}{*}{ Grafting Procedure } & \multirow[b]{2}{*}{ No. of Patients } & \multicolumn{3}{|c|}{ No. of Grafts } \\
\hline & & FIMA & Saph. Vein & Total \\
\hline $\begin{array}{l}\text { Single FIMA } \\
\text { Double FIMA } \\
\text { Single FIMA + } 1 \text { vein graft } \\
\text { Single FIMA + } 2 \text { vein grafts } \\
\text { Double FIMA + } 1 \text { vein graft } \\
\text { Double FIMA + } 2 \text { vein grafts }\end{array}$ & $\begin{array}{r}13 \\
16 \\
9 \\
7 \\
26 \\
6\end{array}$ & $\begin{array}{r}13 \\
9 \\
9 \\
7 \\
52 \\
12\end{array}$ & $\begin{array}{l}\overline{-} \\
99 \\
14 \\
12\end{array}$ & $\begin{array}{l}13 \\
32 \\
18 \\
21 \\
78 \\
24\end{array}$ \\
\hline & 77 & 125 & 61 & 186 \\
\hline
\end{tabular}

FIMA-Free internal mammary artery. 


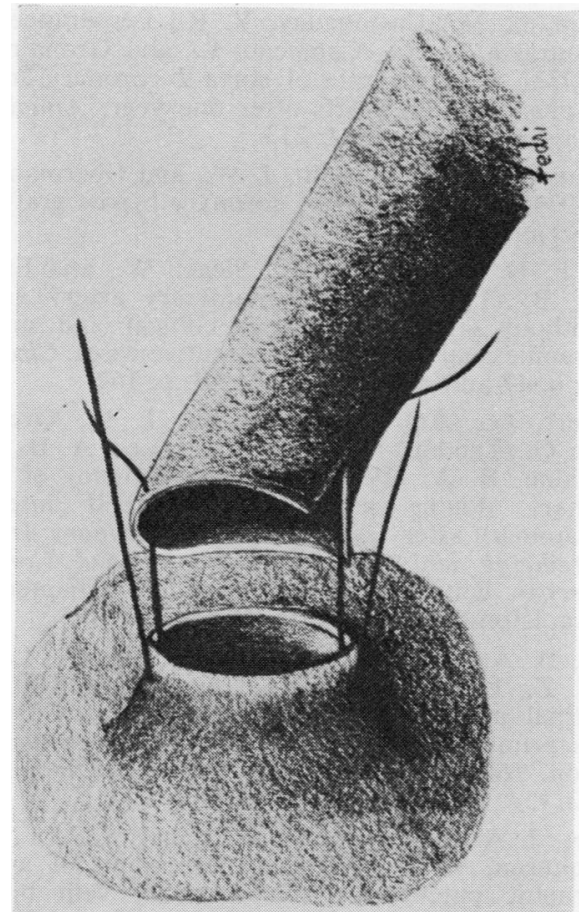

FIG. 1. The vein patch and free IMA at the beginning of the anastomosis.

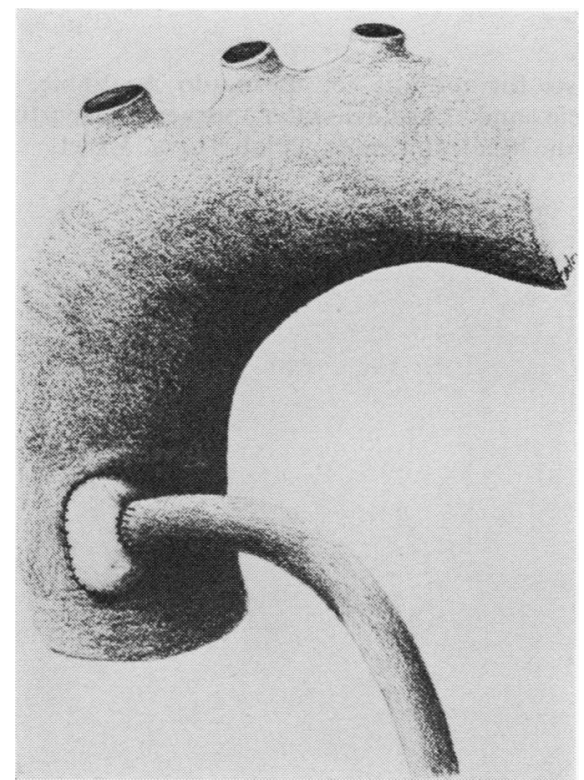

FIG. 2. Artistic representation of the free IMA-vein patch-aortic anastomosis.

\section{RESULTS}

In 77 consecutive patients who underwent myocardial revascularization with free IMA grafts using this vein patch technique there were two hospital deaths. The first patient was a reoperation after failure of a previously placed vein graft. The second was a 68-year-old patient with atrial septal defect and pulmonary hypertension who had four grafts inserted. The patient died because of pulmonary complications. One additional patient died four months after a left ventricular aneurysmectomy and free IMA graft to the right coronary artery. On postmortem examination both patients' grafts were found to be open.

Postoperative electrocardiographic changes of myocardial infarctions were found in only one patient $(1 \cdot 2 \%)$.

Sixty-five of the 74 surviving patients have been re-studied by coronary arteriography two weeks to one year after surgery. Of the 97 free IMA grafts re-studied, $93(96 \%)$ were patent and $4(4 \%)$ were partially or completely occluded. Of 45 additional saphenous vein grafts performed in these 65 patients re-studied, $35(77 \%)$ were patent and $10(23 \%)$ occluded (Table V). The free IMA graft lumen on the postoperative angiographic study appeared consistently greater than is usually seen in undetached IMA grafts. Postoperative left ventricular ejection fraction was performed in 32 patients. In seven patients with poor preoperative ejection fraction, significant improvement of the left ventricular contractility was found.

Of the 74 surviving patients, 71 had no angina and have returned to a moderate active exercise level. Three patients complained of angina on exercise. Coronary arteriography showed that in two of these patients one of the grafts occluded. The third patient had long-standing preoperative arrhythmia. The arrhythmia was not eliminated by the bypass grafts, and the patient continued to take anti-arrhythmic medication.

\section{DISCUSSION}

Several factors are considered to be responsible for the superiority of the internal mammary artery grafts. These are arterial wall, uniform size, and decreased tendency to kink. The above factors obviously will enhance normal flow pattern, preventing postoperative thrombosis. Unfortunately, with undetached internal mammary artery only the descending and the diagonal coronary artery can be grafted safely, provided the heart is not enlarged. In detaching the internal mammary 
artery from its origin and re-anastomosing it to the ascending aorta, greater mobility is obtained. However, direct anastomosis of a small, thinwalled vessel to a much larger and thicker aortic wall, often deformed by atherosclerotic changes, is either impossible, or can produce functional or anatomical stenosis leading to thrombosis of the graft. The intercalation of a vein patch at the aortic end of the graft assures patency of the anastomosis, and intraoperative flow measurement through the IMA shows a $75-350 \mathrm{ml} / \mathrm{min}$ (average $135 \mathrm{ml} / \mathrm{min}$ ) blood flow. This take-off virtually reduplicates the coronary ostium, utilizing lateral pressure in the ascending aorta to promote blood flow during the diastolic phase.

The time spent on the additional anastomosis adds little to the total operating time because it is done outside the chest by a second team.

The high occlusion rate in the saphenous vein grafts can be explained by their insertion into the less advantageous vessels. The free IMA grafts were primarily inserted into the LAD, diagonal or first marginal. These vessels are obviously better recipients than the second marginal, terminal circumflex, distal right, or posterior descending coronary artery.

Our early experience with this technique is very encouraging. Whether a free IMA graft, as used by us, will increase the long-term patency rate can be determined only by prolonged follow-up.

\section{REFERENCES}

Greene, G. E. (1972). Internal mammary artery-tocoronary artery anastomosis. Annals of Thoracic Surgery, 14, 260.
Grondin, C. M., Castonguay, Y. R., Lespérance, J., Bourassa, M. G., Campeau, L., and Grondin, P. (1972). Attrition rate of aorta-to-coronary artery saphenous vein grafts after one year. Annals of Thoracic Surgery, 14, 223.

Kouchoukos, N. T., Kirklin, J. W., and Oberman, A. (1974). An appraisal of coronary bypass grafting. Circulation, 50, 11.

Loop, F. D., Spampinato, N., Siegel, W., and Effler, D. B. (1973). Internal mammary artery grafts without optical assistance; clinical and angiographic analysis of 175 consecutive cases. Circulation, 47 and 48, Supplement III, p. 162.

Schimert, G., Arani, D., Bunnell, I. L., Greene, D. G., Tandon, R., Lajos, T. Z., Lee, A. B., and Vidne, B. A. (1975). Improved patency of coronary double graft with bilateral internal mammary artery anastomosis. In Coronary Artery Medicine and Surgery: Concepts and Controversies, edited by John C. Norman, Chapter 61 . Appleton-Century-Crofts, New York.

Vidne, B. A., Bunnell, I. L., Greene, D. G., Lajos, T. Z., Lee, A. B., and Śchimert, G. (1975). Internal mammary artery graft: coronary bypass as primary method of myocardial revascularization. New York State Journal of Medicine, 75, 1211.

Walker, J. A., Friedberg, H. D., Flemma, R. J., and Johnson, W. D. (1974). Determinants of angiographic patency of aortocoronary vein bypass grafts. Circulation, 44, Supplement II, p. 108.

Requests for reprints to: Bernardo A. Vidne, MD, Thoracic and Cardiovascular Surgery Department, Beilinson Medical Center, Petah-Tiqva, Israel. 